\title{
Results of elective repair at 6 months or younger in 277 patients with tetralogy of Fallot: A 14-year experience at a single center
}

\author{
Roxanne E. Kirsch, MD, ${ }^{a}$ Andrew C. Glatz, MD, MSCE, ${ }^{b}$ J. William Gaynor, MD, \\ Susan C. Nicolson, MD, ${ }^{a}$ Thomas L. Spray, MD, ${ }^{\mathrm{c}}$ Gil Wernovsky, MD, ${ }^{\mathrm{a}, \mathrm{b}}$ and Geoffrey L. Bird, MD ${ }^{\mathrm{a}, \mathrm{b}}$
}

Objective: To report practice and outcomes in infants undergoing elective repair of tetralogy of Fallot.

\begin{abstract}
Methods: A review of a retrospective cohort of elective complete repair of infants age 6 months or younger from 1995 to 2009 was performed. Patients were excluded because of previous interventions, hypercyanotic episodes, intensive care admissions, additional major cardiac defects, or if they were not discharged after birth. Length of stay, mortality, and complications were recorded. Association was determined using logistic or linear regression models and univariate testing determined the multivariate model.
\end{abstract}

Results: There were 277 patients included. The hospital mortality rate was zero. A total of $87.4 \%$ of patients were discharged home within 7 days of repair, and $21.6 \%$ of patients were discharged on or before the third postoperative day. The postoperative course was uncomplicated in 245 patients $(88.4 \%)$. Longer support time was associated independently with increased odds of complications $(P<.001)$. Longer support time, younger age, chromosomal abnormality, and presence of a complication were associated independently with a longer hospital stay (all $P<.001)$. Patients younger than 3 months $(\mathrm{n}=110)$ had a longer median hospital stay (4 vs 3 days; $P<.001)$ and longer support times $(77.3 \pm 35.1 \mathrm{~min}$ vs $66.4 \pm 34 \mathrm{~min} ; P<.01)$.

Conclusions: Elective tetralogy of Fallot repair was performed at 6 months or younger with low morbidity, no hospital mortality, and an $11.6 \%$ complication rate. Longer support times, lower weight, chromosomal abnormalities, and complications were associated with a significantly increased duration of hospital stay. (J Thorac Cardiovasc Surg 2014;147:713-7)

Surgical intervention for tetralogy of Fallot (TOF) during infancy has become routine in many centers since the first successful "correction" by Lillehei et al ${ }^{1}$ more than 50 years ago, ${ }^{2,3}$ and acceptable outcomes into young adulthood have been described..$^{4-8}$ Most centers in the world have, by consensus, planned elective repair early in life in patients with TOF, however, the optimal timing of elective surgical intervention continues to be controversial. ${ }^{6,9-13}$

The literature includes reports of theoretical long-term advantages of primary repair at younger ages, ${ }^{4,6,9,14}$ and experience with repair in early infancy. ${ }^{6,15-20}$ In contrast to extensive literature reporting good results with repair in symptomatic infants, ${ }^{7-9,11,12,21-23}$ there are relatively limited data concerning the elective repair of infants with TOF. ${ }^{15}$ Centers reporting good results note an increased length of stay (LOS) and increased morbidity in patients

\footnotetext{
From the Division of Critical Care, ${ }^{\mathrm{a}}$ Department of Anesthesiology and Critical Care Medicine, Division of Cardiology, ${ }^{\mathrm{b}}$ Department of Pediatrics, and Division of Cardiothoracic Surgery, ${ }^{\mathrm{c}}$ Department of Pediatric Surgery, Cardiac Center at the Children's Hospital of Philadelphia, Philadelphia, Pa.

Funding: This study was internally funded and did not receive external grants or support.

Disclosures: Authors have nothing to disclose with regard to commercial support.

Received for publication Oct 18, 2012; revisions received Feb 15, 2013; accepted for publication March 20, 2013; available ahead of print April 22, 2013.

Address for reprints: Roxanne E. Kirsch, MD, Children's Hospital of Philadelphia, 324 South 34th St, Main Building, Room 6NE46, Philadelphia, PA 19104-4399 (E-mail: kirschr@email.chop.edu).

$0022-5223 / \$ 36.00$

Copyright (c) 2014 by The American Association for Thoracic Surgery http://dx.doi.org/10.1016/j.jtcvs.2013.03.033
}

younger than 3 months. ${ }^{4,6,19,20,23,24}$ Given the differences in preoperative symptoms and underlying physiology, extrapolating results of symptomatic patients may not best inform a course of action for the elective patient. The purpose of our study was to report surgical practice and perioperative outcomes of a large cohort of infants undergoing elective repair of TOF in a single center, specifically to identify risk factors associated with postoperative complications and LOS.

\section{MATERIALS AND METHODS \\ Study Design}

This was a retrospective cohort study focusing on early surgical results in young infants. Patients with TOF were selected if elective complete surgical repair occurred between January 1, 1995, and January 31, 2009, at 6 months of age or younger. Elective repair was defined as a routinely scheduled surgical procedure in a hemodynamically stable patient without cyanosis requiring therapy. Patients were referred for surgical repair by their cardiologist in consultation with the multidisciplinary care team at our institution. Exclusion criteria were as follows: (1) age older than 6 months, (2) experiencing a hypercyanotic episode requiring intervention; (3) requiring alprostadil, mechanical ventilatory support, morphine, and/or phenylephrine; (4) undergoing prior cardiac surgery or interventional palliation; and (5) having additional major cardiac defects (eg, complete atrioventricular septal defect). In addition, to ensure that our population included patients cared for in a home environment before surgery, we excluded any patient not discharged from the hospital before the TOF repair. Medical records were reviewed for patient demographics, associated cardiovascular anomalies, documented genetic abnormalities, reports of cardiac catheterization, and presence of cyanosis requiring therapy. 


$$
\begin{aligned}
& \text { Abbreviations and Acronyms } \\
& \text { ACC }=\text { aortic cross-clamp } \\
& \text { CPB }=\text { cardiopulmonary bypass } \\
& \text { DHCA }=\text { deep hypothermic circulatory arrest } \\
& \text { LOS }=\text { length of stay } \\
& \text { LSCA }=\text { left subclavian artery } \\
& \text { RAA }=\text { right aortic arch } \\
& \text { TOF }=\text { tetralogy of Fallot } \\
& \text { TST }=\text { total support time }
\end{aligned}
$$

Surgical notes were reviewed for descriptions of repair technique, additional surgical procedures, and duration of intraoperative support (cardiopulmonary bypass $[\mathrm{CPB}]$, aortic cross-clamp [ACC], and deep hypothermic circulatory arrest [DHCA]). The perioperative course was reviewed for length of intensive care unit and hospital stay, early reoperation (within 30 days of surgery or before hospital discharge), and incidence of major organ dysfunction or complications.

Complications were defined as atypical clinical events requiring initiation of unanticipated medical or interventional procedures. Given published reports of prolonged hospital stay, longer intensive care unit stay, and longer duration of inotropic and ventilator support in patients younger than 3 months, ${ }^{4,9,19,20,24}$ we analyzed the cohort using this age cut-off value as a divider. Patients were analyzed in a subgroup of those younger than 3 months age, which included all patients 11.99 weeks and younger (patients $\geq 3$ months were $\geq 12$ weeks). The Institutional Review Board at The Children's Hospital of Philadelphia approved the study, and informed consent was waived.

\section{Statistical Methods}

Standard descriptive statistics were used to summarize the data and were expressed as mean \pm standard deviation for normally distributed continuous variables, as median with range for skewed continuous variables, and as count with a percentage of the total for categoric variables. Differences in covariates based on age at surgery ( $<3 \mathrm{vs} \geq 3$ months) were tested using the Student $t$ test, the Wilcoxon rank sum test, or the chi-square test as appropriate. Measures of association between potential risk factors and outcomes of interest were assessed using logistic regression for dichotomous outcome variables (complications), and linear regression for continuous outcome variables (natural log-transformed length of hospital stay). Covariates with a $P$ value less than .2 in univariate testing were considered for inclusion in a multivariable model and were retained in the final model if the $P$ value was less than .05 or if there was evidence for significant confounding or effect modification. Statistical significance was established at a 2 -tailed $P$ value less than .05. All statistical analyses were performed using STATA version 10 (Stata Corp, College Station, Tex).

\section{RESULTS \\ Preoperative Data}

Between January 1, 1995, and January 31, 2009, there were 603 patients with TOF who were admitted for surgical repair, of whom 277 met inclusion criteria and constituted our study cohort. Demographic, anatomic, clinical, surgical, and outcome characteristics of the cohort are summarized in Table 1 . The median age at repair was 104 days (3.46 months) and 110 patients were younger than 3 months. At the time of chart review, 44 patients $(16.7 \%)$ were noted to have chromosomal abnormalities. Thirteen patients $(5 \%)$
TABLE 1. Summary of demographic, clinical, surgical, and outcome characteristics of the study cohort $(n=277)$

\begin{tabular}{lc}
\hline Demographic and clinical variables & \\
Male & $158(57 \%)$ \\
Age at surgery $(\mathrm{d})$ & $104(20-209)$ \\
Weight at surgery $(\mathrm{kg})$ & $5.4(2.4-9.6)$ \\
22q11 microdeletion & $19(7.2 \%)$ \\
Trisomy 21 & $18(6.6 \%)$ \\
Any chromosomal abnormality & $44(16.7 \%)$ \\
History of prematurity (<38 wk gestation) & $23(8.3 \%)$ \\
RAA with mirror image branching & $65(23.5 \%)$ \\
RAA with aberrant left subclavian artery & $14(5.1 \%)$ \\
LAA with aberrant right subclavian artery & $3(1.1 \%)$ \\
Left SVC to coronary sinus & $21(7.6 \%)$ \\
Additional VSD & $19(6.9 \%)$
\end{tabular}

Surgical variables

Use of DHCA

DHCA time $(\mathrm{n}=64)(\mathrm{min})$

$64(23.1 \%)$

$34(10-61)$

ACC time (min)

$35(14-111)$

CPB time (min)

$63(18-201)$

TST $(\mathrm{DHCA}+\mathrm{CPB})(\min )$

$66(18-201)$

More than 1 bypass run

$14(5.1 \%)$

Approach to close ventricular septal defect

Atrial

$194(70.3 \%)$

Ventricular

$70(25.4 \%)$

Combined

$12(4.4 \%)$

Use of transannular patch

$187(67.5 \%)$

Right ventricular muscle bundle resection $\quad 210(75.8 \%)$

Residual atrial communication

$230(83.6 \%)$

Postoperative course

Length of intensive care unit stay (d) $3(1-82)$

Length of total hospital stay (d)

$5(2-118)$

Length of stay, $>7 \mathrm{~d}$

$35(12.6 \%)$

Complication*

CPR

$32(11.6 \%)$

$6(2.2 \%)$

ECMO

$3(1.1 \%)$

Reoperation for bleeding

$10(3.6 \%)$

Reoperation for residual lesion $3(1.1 \%)$

Reoperation for pacemaker $\quad 1(0.4 \%)$

Catheterization (diagnostic) $3(1.1 \%)$

Catheterization (interventional) $1(0.4 \%)$

Pleural/pericardial drain placement $\quad 8(2.9 \%)$

Re-intubation $7(2.5 \%)$

Tracheostomy $3(1.1 \%)$

Stroke $2(0.7 \%)$

Data are presented as median (range) or count (\% of total). $C P R$, Cardiopulmonary resuscitation; $E C M O$, extracorporeal membrane oxygenator; $L A A$, left aortic arch; $S V C$, superior vena cava; $R A A$, left aortic arch; $D H C A$, deep hypothermic circulatory arrest; $A C C$, aortic cross-clamp; $C P B$, cardiopulmonary bypass; TST, total support time; VSD, ventricular septal defect. $* 48$ total complications occurred in 32 patients.

had either no record of chromosomal abnormality, or an unknown chromosomal anomaly.

\section{Surgical Data}

Surgical interventions are summarized in Table 1. A transannular patch was used in the majority $(187 ; 67.5 \%)$ of patients. There was a trend toward greater use of 
TABLE 2. Variables significantly associated with postoperative complications (by logistic regression)

\begin{tabular}{|c|c|c|c|c|c|c|}
\hline \multirow[b]{2}{*}{ Covariate } & \multicolumn{2}{|c|}{ Complication } & \multicolumn{2}{|c|}{ Univariate } & \multicolumn{2}{|c|}{ Multivariate } \\
\hline & Yes $(n=32)$ & No $(n=245)$ & OR $(95 \%$ CI $)$ & $\boldsymbol{P}$ & OR $(95 \%$ CI $)$ & $\boldsymbol{P}$ \\
\hline Weight at surgery $(\mathrm{kg})$ & $4.95(2.9-7.5)$ & $5.5(2.4-9.6)$ & $0.69(0.5-0.97)$ & .034 & & \\
\hline Use of DHCA & $14(43.8 \%)$ & $50(20.4 \%)$ & $3(1.4-6.5)$ & .004 & & \\
\hline $\mathrm{DHCA}(\min )$ & $42.5(26-61)$ & $32(10-60)$ & $1.13(1.04-1.22)$ & .003 & & \\
\hline $\mathrm{ACC}(\mathrm{min})$ & $45.5(16-93)$ & $34(14-111)$ & $1.03(1.01-1.05)$ & .002 & & \\
\hline $\mathrm{CPB}(\min )$ & $81.5(26-138)$ & $58(18-201)$ & $1.03(1.01-1.04)$ & $<.001$ & & \\
\hline Total support time (min) & $93(26-199)$ & $61(18-201)$ & $1.02(1.01-1.03)$ & $<.001$ & $1.02(1.01-1.04)$ & $<.001$ \\
\hline RAA with aberrant LSCA & $4(12.5 \%)$ & $10(4.1 \%)$ & $3.4(1-11.4)$ & .05 & $4.8(1.3-18)$ & .02 \\
\hline Left SVC to coronary sinus & $6(18.8 \%)$ & $15(6.1 \%)$ & $3.5(1.3-9.9)$ & .016 & & \\
\hline
\end{tabular}

Data are presented as median (range) or count (percentage of total). $C I$, Confidence interval; $O R$, odds ratio; $S V C$, superior vena cava; $D H C A$, deep hypothermic circulatory arrest; $A C C$, aortic cross-clamp; $C P B$, cardiopulmonary bypass; $R A A$, left aortic arch; $L S C A$, left subclavian artery.

transatrial ventricular septal defect closure over time. An inter-atrial communication was created or maintained in 230 patients $(83 \%)$, and was closed or not created in 45 patients $(16.2 \%)$. Data regarding the status of the atrial septum were missing in 2 patients.

For the purposes of this study, total support time (TST) was the sum of time spent on CPB plus DHCA (if used). Thus, if no DHCA was used, CPB time equaled TST. DHCA was used in 64 patients $(23.1 \%)$ with a median duration of 34 minutes, and use declined dramatically after the first year of the study ( 14 of $15 ; 93.3 \%$ ) to the last year of the study ( 2 of $24 ; 8.3 \%$ ). DHCA was used at the surgeon's discretion and exact criteria were not available for review. Median ACC and TST times were 35 and 66 minutes, respectively, over 14 years. There was a progressive decrease in median TST from 102 minutes in 1995 to 38 minutes in 2008 . The annual surgical volume increased over the same time period.

\section{Mortality}

The hospital mortality rate in this cohort was zero.

\section{Morbidity}

Hospital and intensive care unit LOS for the cohort are summarized in Table 1. The median duration of hospitalization in the intensive care unit was 3 days (range, 1-82 days), with an overall trend toward a shorter hospital stay over the duration of the series. The majority of patients (242; $87.4 \%$ ) were discharged home within 7 days of elective surgical repair (Table 1); 21.6\% (60 patients) were discharged on or before the third postoperative day.

Although the postoperative course was uncomplicated in 245 patients $(88.4 \%)$, a wide range of complications occurred (Table 1). Six patients required cardiopulmonary resuscitation, 3 of whom had a return of spontaneous circulation, and 3 patients were rescued with extracorporeal membrane oxygenation support. Ten patients $(3.6 \%)$ required reoperation for bleeding, and 3 patients required reoperation for residual lesions. In total, 4 patients $(1.4 \%)$ required reoperation (3 for residual defects, 1 for a permanent pacemaker), and 1 patient required reintervention $(0.3 \%)$ with the placement of a left pulmonary artery stent before discharge. In total, 48 complications occurred in 32 patients. There was no surgeon effect found that remained significant after TST was controlled for, although the majority of surgeries (159) were performed by a single surgeon.

Table 2 summarizes the potential risk factors associated with postoperative complications. In univariate analysis, lower weight at surgery, longer surgical support times, the use of DHCA, a right aortic arch (RAA) with an aberrant left subclavian artery (LSCA), and a left superior vena cava to coronary sinus were associated with increased odds of measured complications. However, with multivariate analysis, only TST $(P<.001)$ and RAA with an aberrant LSCA $(P=.02)$ were associated independently with higher complication rates. Risk factors for hospital LOS (Table 3) by univariate analysis showed an association with weight at surgery, use of DHCA, lengths of DHCA, ACC, CPB, and TST, as well as RAA with aberrant LSCA. With multivariate analysis, longer TSTs $(P<.001)$, younger age at surgery $(P<.001)$, presence of a chromosomal abnormality $(P<.001)$, and presence of a postoperative complication $(P<.001)$ were associated independently with longer LOS.

Patients younger than 3 months of age had a 1-day longer median hospital stay that reached statistical significance (5 vs 4 days; $P<.001$ ). There was also an 11 -minute increase in TST in the group that was younger than 3 months $(77.3 \pm 35.1 \mathrm{~min}$ vs $66.4 \pm 34 \mathrm{~min} ; P<.01)$. A transannular patch was used more frequently in those younger than 3 months (89 patients [80.9\%] vs 98 patients [58.7\%]; $P<.001)$. The incidence of complications was not statistically significantly higher in the those younger than 3 months $(15.5 \%)$ versus those 3 months or older $(9 \%)(P=.1)$.

\section{DISCUSSION}

In this retrospective review spanning 14 years, elective repair in infancy resulted in no mortality, a hospital LOS less than 1 week in $87.4 \%$ of patients, and an $11.6 \%$ complication rate. Not unexpectedly, the presence of 
TABLE 3. Variables significantly associated with hospital LOS (by linear regression, using natural log-transformed LOS)

\begin{tabular}{|c|c|c|c|c|}
\hline \multirow[b]{2}{*}{ Covariate } & \multicolumn{2}{|c|}{ Univariate } & \multicolumn{2}{|c|}{ Multivariate } \\
\hline & Coefficient $(95 \%$ CI $)$ & $\boldsymbol{P}$ & Coefficient $(95 \%$ CI $)$ & $P$ \\
\hline Age at surgery (mo) & $-0.1(-0.15$ to -0.05$)$ & $<.001$ & $-0.07(-0.1$ to -0.04$)$ & $<.001$ \\
\hline Weight at surgery $(\mathrm{kg})$ & $-0.12(-0.17$ to -0.06$)$ & $<.001$ & & \\
\hline Chromosomal abnormality & $0.42(0.24-0.6)$ & $<.001$ & $0.31(0.18-0.44)$ & $<.001$ \\
\hline Use of DHCA & $0.38(0.22-0.53)$ & $<.001$ & & \\
\hline DHCA (min) & $0.02(0.006-0.04)$ & .008 & & \\
\hline $\mathrm{ACC}(\mathrm{min})$ & $0.01(0.009-0.02)$ & $<.001$ & & \\
\hline $\mathrm{CPB}(\min )$ & $0.01(0.008-0.013)$ & $<.001$ & & \\
\hline TST (min) & $0.008(0.006-0.01)$ & $<.001$ & $0.005(0.003-0.006)$ & $<.001$ \\
\hline Left SVC to coronary sinus & $0.4(0.15-0.65)$ & .002 & & \\
\hline VSD closed through ventricle & $0.26(0.11-0.4)$ & .001 & & \\
\hline Postoperative complication & $1.07(0.9-1.2)$ & $<.001$ & $0.92(0.76-1.1)$ & $<.001$ \\
\hline
\end{tabular}

$C I$, Confidence interval; $S V C$, superior vena cava; $V S D$, ventricular septal defect; $D H C A$, deep hypothermic circulatory arrest; $A C C$, aortic cross-clamp; $C P B$, cardiopulmonary bypass; $T S T$, total support time.

a postoperative complication increased hospital LOS. In addition, TST, younger age at surgery, and the presence of a chromosomal abnormality increased hospital LOS.

The rate of early reoperation for hemodynamically significant residual lesions in our series of $1.4 \%$ ( 4 of 277) was similar to that reported elsewhere. . $-6,8,11,15-17,19,24^{-1}$

Although an association was found between RAA with aberrant LSCA and increased complications, we could postulate no cause of this association in a retrospective review. These patients did not have a higher incidence of the 22q11 deletion. Longer TST also was associated with increased complications. We did not show any increase in postoperative complications in the younger $(<3$ months) age group when compared with the 3 month and older group as a subset, although by logistic regression we noted that younger age was associated with a median 1-day longer hospital stay. Also, the presence of genetic anomalies was associated with a longer hospital stay. This was also found in other studies. ${ }^{25}$ Overall, our patients had a relatively short LOS, and 242 patients $(87.4 \%)$ were discharged by 7 days after surgery in this series.

Limitations of our study were similar to those of other retrospective reviews. Results from our single center may not be generalizable and review of the medical records left some questions about our patients unanswered. Specifically, we were not able to accurately obtain an incidence of postoperative arrhythmias, and we did not have sufficient data to extend our study to important longer-term outcomes. Although longer-term physiologic and quality-of-life outcomes are exceedingly important to assess this approach, these findings were beyond the scope of this study and will be the subject of future investigations.

We advocate repair of asymptomatic infants with TOF in early infancy. Waiting beyond the neonatal period allows for a decrease in pulmonary vascular resistance and maturation of other organ systems (eg, the kidney), which may improve the postoperative course after $\mathrm{CPB}$, and may be better tolerated by the central nervous system. However, an excessive delay in repair may result in prolonged hypoxemia, the risk of sudden hypercyanotic spells, as well as significant right ventricular hypertrophy that may complicate the surgical exposure and lead to diastolic dysfunction that complicates the postoperative course. Because of the expected right ventricular dysfunction at any age, an additional management strategy used in the great majority of cases was the intentional use of a limited interatrial communication. We believe this feature allows for left atrial filling and maintenance of left ventricular output at times in the postoperative course when right heart dysfunction is limiting effective pulmonary blood flow. However, the benefits of an early postoperative pretricuspid shunt must be weighed against the concerns of potential residual atrial defects over time. Our results support the hypothesis that elective repair of TOF can be performed in early infancy with low morbidity, a short hospital stay, and a low mortality rate (none in this series) in the great majority of patients. We suggest elective repair is performed acceptably in early infancy, and data obtained in this retrospective review suggest that elective repair at age 3 to 6 months is associated with improved outcome for patients who are asymptomatic.

We wish to acknowledge Drs Marshall L. Jacobs, MD, William M. DeCampli, MD, PhD, Tom R. Karl, MD, and Peter J. Gruber, $\mathrm{MD}, \mathrm{PhD}$, who performed surgery on some of the patients in this series, as well as the nurses, anesthesiologists, cardiologists, intensivists, and therapists who cared for these children and their families. The authors also acknowledge the contribution of Lisa Jones, $\mathrm{RN}$, and Peter Pastuszko, MD, for assistance with data collection.

\section{References}

1. Lillehei CW, Cohen M, Warden HE, Read RC, Aust JB, Dewall RA, et al. Direct vision intracardiac surgical correction of the tetralogy of Fallot, pentalogy of Fallot, and pulmonary atresia defects; report of first ten cases. Ann Surg. 1955;142: 418-43.

2. Hennein HA, Mosca RS, Urcelay G, Crowley DC, Bove EL. Intermediate results after complete repair of tetralogy of Fallot in neonates. J Thorac Cardiovasc Surg. 1995;109:332-42. 
3. Sousa UM, Chardigny C, Galetti L, Lacour Gayet F, Roussin R, Serraf A, et al. Surgery for tetralogy of Fallot at less than six months of age. Is palliation "oldfashioned"? Eur J Cardiothorac Surg. 1995;9:453-9.

4. Kantorova A, Zbieranek K, Sauer H, Lilje C, Haun C, Hraska V. Primary early correction of tetralogy of Fallot irrespective of age. Cardiol Young. 2008;18: 153-7.

5. Lindberg HL, Saatvedt K, Seem E. Single-center 50 years' experience with surgical management of tetralogy of Fallot. Eur J Cardiothorac Surg. 2011;40: 538-42.

6. Tamesburger MI, Lechner E, Mair R, Hofer A, Sames-Dolzer E, Tulzer G. Early primary repair of tetralogy of Fallot in neonates and infants less than four months of age. Ann Thorac Surg. 2008;86:1928-36.

7. Al Habib HF, Jacobs JP, Mavroudis C, Tchervenkov CI, O'Brien SM, Mohammadi S, et al. Contemporary patterns of management of tetralogy of Fallot: data from the Society of Thoracic Surgeons database. Ann Thorac Surg. 2010;90:813-20.

8. Hirsch JC, Mosca RS, Bove EL. Complete repair of tetralogy of Fallot in the neonate. Ann Thorac Surg. 2000;232:508-14.

9. Bove T, Francois K, Van De Kerckhove K, Panzer J, De Groote K, De Wolf D, et al. Assessment of a right-ventricular infundibulum-sparing approach in transatrial-transpulmonary repair of tetralogy of Fallot. Eur J Cardiothorac Surg. 2012;41:126-33.

10. Derby CD, Pizarro C. Routine primary repair of tetralogy of Fallot in the neonate. Expert Rev Cardiovasc Ther. 2005;3:857-63.

11. Bacha EA, Scheule AM, Zurakowske D, Erickson LC, Hung J, Lang P, et al. Long-term results after early primary repair of tetralogy of Fallot. J Thorac Cardiovasc Surg. 2001;122:154-61.

12. Van Ardsell G, Yun T-J. An apology for primary repair of tetralogy of Fallot. Semin Thorac Cardiovasc Surg Pediatr Card Surg Ann. 2005;8:128-31.

13. Vohra HA, Adamson L, Haw MP. Is early primary repair for correction of tetralogy of Fallot comparable to surgery after 6 months of age? Int Cardiovasc Thorac Surg. 2008;7:698-701

14. Reddy VM, Liddicoat JR, McElhinney DB, Brook MM, Stanger P, Hanley FL. Routine primary repair of tetralogy of Fallot in neonates and infants less than three months of age. Ann Thorac Surg. 1995;60:S592-6.
15. Parry AJ, McElhinney DB, Kung GC, Reddy VM, Brook MM, Hanley FL. Elective primary repair of acyanotic tetralogy of Fallot in early infancy: overall outcome and impact on the pulmonary valve. J Am Coll Cardiol. 2000;36: 2279-83.

16. Alexiou C, Chen Q, Galogavrou M, Gnanapragasam J, Salmon AP, Keeton BR et al. Repair of tetralogy of Fallot in infancy with a transventricular or a transatrial approach. Eur J Cardiothorac Surg. 2002;22:174-83.

17. Alexiou C, Mahmoud H, Al Khaddour A, Gnanapragasam J, Salmon AP, Keeton BR, et al. Outcome after repair of tetralogy of Fallot in the first year of life. Ann Thorac Surg. 2001;71:494-500.

18. Dyamenahalli U, McCrindle BW, Barker GA, Williams WG, Freedom RM, Bohn DJ. Influence of perioperative factors on outcomes in children younge than 18 months after repair of tetralogy of Fallot. Ann Thorac Surg. 2000;69: 1236-42.

19. Van Arsdell GS, Maharaj GS, Tom J, Rao VK, Coles JG, Freedom RM, et al What is the optimal age for repair of tetralogy of Fallot? Circulation. 2000; 102:123-9.

20. van Dongen EI, Glansdorp AG, Mildner RJ, McCrindle BW, Sakopoulos AG, VanArsdell G, et al. The influence of perioperative factors on outcomes in children aged less than 18 months after repair of tetralogy of Fallot. J Thorac Cardiovasc Surg. 2003;126:703-10.

21. Lee JR, Kim JS, Lim HG, Hwang HY, Kim YJ, Rho JR, et al. Complete repair of tetralogy of Fallot in infancy. Interact Cardiovasc Thorac Surg. 2004;3:470-4.

22. Park CS, Kim WH, Kim GB, Bae EJ, Kim JT, Lee JR, et al. Symptomatic young infants with tetralogy of Fallot: one-stage versus staged repair. J Card Surg. 2010; 25:394-9.

23. Lee C, Lee C-H, Kim S-C, Lim C, Chang YH, Kang CH, et al. Outcome after one-stage repair of tetralogy of Fallot. J Cardiovasc Surg (Torino). 2006;47: 65-70.

24. Ooi A, Moorjani N, Baliulis G, Keeton BR, Salmon AP, Monro JL, et al. Medium term outcome for infant repair in tetralogy of Fallot: indicators for timing of surgery. Eur J Cardiothorac Surg. 2006;30:917-22.

25. Mercer-Rosa L, Pinto N, Yang W, Tanel R, Goldmuntz E. 22q11 Deletion syndrome is associated with perioperative outcome in tetralogy of Fallot. $J$ Thorac Cardiovasc Surg. 2013. Epub ahead of print. 